\title{
Public Attention and Head-to-Head Campaign Fundraising: An Examination of U.S. Senate Elections
}

\author{
William Curtis Ellis \\ Oral Roberts University \\ wellis@oru.edu \\ Joseph T. Ripberger \\ University of Oklahoma \\ jtr@ou.edu
}

\section{Douglas Swearingen \\ John Carroll University \\ cswearingen@jcu.edu}

Does public attention to political candidates impact fundraising margins in U.S. Senate elections? Applying a novel conceptualization of public attention, we examine U.S. Senate elections from 2004 through 2014 and find that increases in relative public attention relate to increases in head-to-head fundraising margins in open seat races. We conclude by asking whether or not all attention to candidates is "good" attention. Evidence from the 2006 Allen/Webb election suggests that all attention is not "good" attention. This race demonstrates that candidates can supply attention-grabbing action that increases relative public attention while stimulating exceptional losses in relative fundraising margins. Further research must clearly theorize conditions under which supplying public attention-grabbing behavior may damage political campaigns.

\section{Introduction}

Fundraising is critical to campaign success in congressional elections - winners raise and spend a lot of money (Jacobson 1992; Krasno, Green, and Cowden 1994; Grier 1989; Gerber 1998; Epstein and Zemsky 1995; Adams and Squire 1997). Similarly, fundraising success indirectly contributes to election success by scaring away potential opponents (Epstein and Zemsky 1995; Squire and Wright 1990). Thus, if candidates want to win elections, they will engage in fundraising (Krasno, Green, and Cowden 1994). However, our understanding of what drives fundraising success limits the predictability of campaign-fundraising success to ad hoc observations of experiential candidate characteristics and structural factors that do not allow for theoretical extrapolations predicting fundraising success during the campaign season. This study explores the key factors of head-to-head campaign fundraising success in an attempt to identify how public attention, as measured by Google Trends search data, can help us better predict a fundamental component of political campaigns.

In House races, empirical evidence demonstrates that candidate experience, name recognition, district population and partisanship, the timing of member retirement, the inertia of campaign successes, and lead-time to establish campaign activity all predict higher fundraising 
totals (Goldenberg and Traugott 1980; Squire and Wright 1990; Krasno, Green, and Cowden 1994; Gimpel, Kaufmann, and Pearson-Merkowitz 2007; Swearingen and Jatkowski 2011). In Senate races, the evidence suggests fundraising is reciprocal within elections (Stewart 1989), and factors such as "pivotal status," ideology, and committee positioning increase total interest group and PAC contributions (Grier 1989; Mixon, Jr., Crocker, and Black 2005).

We argue that candidates who gain a "public attention" advantage over their opponent will earn systematic gains in fundraising success, controlling for other factors. Managing public attention fits into the strategy and purpose of political campaigns. Different than public opinion, which captures "what people think," our concept of public attention captures the public's intentional use of personal resources to process information about political candidates. Two conceptual components distinguish this project from traditional studies of campaign fundraising. First, we explore the impact of head-to-head public attention differences on head-to-head differences with respect fundraising. In so doing, our theory and evidence justify strategic political actions or statements that garner the direct interest and attention of the public relative to their opposition.

Second, to demonstrate these components, we tie our conceptualization of public attention to the fundraising literature and provide the theoretical link between relative public attention and relative fundraising success. We then describe how relative attention is measured and present empirical analyses of Senate general election campaigns from 2004 through 2014 confirming the significant impact of public attention on fundraising success. Head-to-head advantages in attention appear to elicit competitive advantages in total fundraising for Senate campaigns generally and even more so in open seat races. ${ }^{1}$ While these findings suggest that attention is important, not all attention is "good" for candidates and their campaigns. To illustrate this point, we briefly explore the 2006 Senate race in Virginia between then-Senator George Allen and Jim Webb. We conclude that further research should examine how certain campaign actions and events involving candidates may account for the conditions in which public attention becomes "good" or "bad" attention and how campaigns can strategically supply drivers of "good" attention.

\section{Using Public Attention to Predict Fundraising Success in Congressional Campaigns}

In general, we believe the elections and fundraising literature could be expanded in two important ways: by first theoretically and empirically examining factors that may influence headto-head campaign fundraising, and secondly building theoretical leverage to extrapolate towards fluid predictability of head-to-head fundraising successes during campaign cycles. ${ }^{2}$ We define public attention as the scarce resources - time and other - that boundedly rational citizens willingly devote to processing information about a particular topic (Ripberger 2011). Though related, it is not the same thing as public opinion or issue salience. Public opinion (at the macro level) denotes aggregate beliefs, predispositions, and attitudes about a particular topic and public attention captures the amount of resources that members of the public spend thinking about that

\footnotetext{
${ }^{1}$ Replication data is available upon request by emailing the corresponding author.

${ }^{2}$ While Eom and Gross (2006) examine fundraising success, their population is gubernatorial campaigns.
} 
topic. In other words, public opinion taps "what people think," whereas public attention measures "what people think about" (Newig 2004). Issue salience denotes issues that impact the most people (Gormley 1986; Eshbaugh-Soha 2006) or issues people consider to be "most important"(Behr and Iyengar 1985; Wlezien 2005). At times, the two variables are related to one another, but this is not necessarily the case. For instance, an individual voter might have a relatively strong opinion about a particular candidate, even without having spent much time thinking about that candidate. By comparison, another voter might have spent a lot of time thinking about a candidate without having developed an opinion about the candidate. Voters also might consider certain issues to be important when asked, but do not dedicate time or resources exploring the issue. Distinguished from both public opinion - which provides direction of opinion - and issue salience, public attention denotes the active process wherein members of the public selectively allocate limited resources (time and other) towards processing information about a particular signal (or set of signals) while ignoring others (Ripberger 2011). In other words, was a candidate successful in getting her name in the limelight enough that someone was interested in finding more information about her?

In many instances, the signals that compete for and stimulate public attention in the political domain are substantive issues - like the wars in Afghanistan or Iraq, the economy, or global warming (e.g., Flemming, Wood, and Bohte 1999; Henry and Gordon 2001; Zhu 1992; Neuman 1990; Wlezien 2005; Jones and Baumgartner 2005; Jennings and John 2009). During election season, however, political candidates are added to the list of signals that compete for and elicit attention. We argue that campaigns should try to stimulate attention to, or interest in, themselves vis-à-vis their opponent.

Similar to companies selling products or firms seeking capital investment, campaigns must separate themselves from their competition. In the business world, one way that companies/ firms accomplish this is public information or marketing campaigns, designed to elicit public (or sector-specific) attention. People will not go to the store to buy your product if they are not aware that it exists. Recognizing this, companies and firms compete with one another to elicit the most attention. On average, the company that receives the most attention sells more products (Falkinger 2008) and the firm that captures the most attention attracts the most investors (Mondria, $\mathrm{Wu}$, and Zhang 2010). If this is true of campaigns, then the candidates who stimulate more attention than their competitors will, on average, attract more donors, and ultimately, more money. This logic yields our first hypothesis:

\section{$\left(H_{l}\right)$ Candidates with higher relative public attention will raise more money than those candidates with lower relative public attention.}

When considering election campaigns, it is important to note that all elections are not equal. There are effectively two types of elections: races with an incumbent, and open seat races. Compared to races with incumbents, open seat races are unique in that they tend pose a choice between fairly equal candidates (Abramowitz 1988), resulting in high levels of candidate fundraising (Gaddie and Bullock 2000). Likewise, open seat races tend to attract candidates are relatively unknown to potential contributors. Because open seat races often provide the best opportunity for a party to pick up seats (Mayhew 1974), 
having an advantage in fundraising is critical to winning (Lazarus 2008). Thus, it may be that open seat races provide an environment where there battle for public attention and financial resources is particularly intertwined. This consideration yields our second hypothesis:

$\left(\mathrm{H}_{2}\right)$ Candidates with higher relative public attention will raise more money than those candidates with lower relative public attention, particularly in open seat elections.

\section{Data and Measurement}

In order to empirically test the impact of public attention on fundraising in Senate campaigns, the following sections detail an analysis of all Senate elections from 2004 to 2014.

\section{Explanatory Variable - Public Attention}

Similar to a Swearingen and Ripberger's (2014) recent study on U.S. Senate election outcomes, we adopt an Internet search-based measure of public attention. To collect these data, we use Google Trends. ${ }^{3}$ This decision was made for three reasons: First, Google is the most widely used search engine in the United States. According to Hitwise, Google owns approximately $68 \%$ of the US market share, as compared to Yahoo, which is the next closest at roughly 14\% (Ripberger 2011). ${ }^{4}$ As such, collecting data on Google rather than Yahoo or Bing searches yields the largest cross-section to the Internet-using population. Second, the vast majority of social scientists, and scientists in other disciplines such as epidemiology, utilizing search-based measures of public attention have used Google Insights, further validating the data studies (Granka 2013; Mellon 2013; Reilly, Richey, and Taylor 2012; Scharkow and Vogelgesang 2011; Scheitle 2011; Gruszczynski and Wagner 2010; Ayers, Rubisl, and Brownstein 2011; Askitas and Zimmermann 2009; Pelat et al. 2009; Koehler-Derrick 2013; Mccallum and Bury 2013; Ragas and Tran 2013; Zheluk et al. 2013). Finally, we decided to use Google Trends because it is freely available and easy to access, enhancing the ability of future researchers to replicate and expand upon this research.

Collecting data by way of Google Trends involves a two-step process. First, users are prompted to enter up to five search terms or keywords that they would like to analyze. Next, users are asked if they would like to filter their query by geographic location, category, or timeframe (Google Trends dates back to 2004). After the user completes these two steps, Google Trends will generate a dataset that estimates search volume for the specified keywords during the specified time and within the specified region. These estimates, which can be downloaded to a .csv file, represent relative volumes that are normalized by region and scaled by dividing the search volume at each point in time (e.g. week or month) by the estimated search volume at the highest point in time and multiplying by 100 . The end result is a series of data points ranging

\footnotetext{
3 To access Google Insights for Search, visit http://www.google.com/trends/explore.

${ }^{4}$ According to StatCounter, another prominent web analytics provider, Google's market share is much higher, accounting for approximately $81 \%$ of the search engine market (Ripberger 2011).
} 
from 0 to 100 , where 100 represents the point at which search activity for the most popular keyword that the user has entered was the most intensive.

In order to measure relative public attention, we entered the first and last name of the two major party candidates for each Senate contest as keywords in Google Trends. We then filtered our results by the state in which the campaign was waged and the timeframe of January through November of each election year. After downloading our results, we computed an attention score for each candidate by averaging the amount of relative attention that he or she received between January and November of the election year. ${ }^{5}$ Relative public attention, which is the variable utilized in subsequent analyses, was calculated by subtracting the attention score of the Republican Party candidate from the attention score of the Democratic Party candidate. ${ }^{6}$ A positive attention margin indicates that the Democratic Party candidate received more public attention than the Republican Party candidate. Descriptive statistics for our measure of relative public attention and the control variables we included in our models can be found in the Appendix.

\section{Dependent Variable}

The dependent variable in this study is relative fundraising, which we measure in three different ways. First, we use total fundraising based on relative campaign receipts by subtracting the total amount of money raised by the Republican Party candidate from the total amount of money raised by the Democratic Party candidate (in $\$ 100,000$ s), as reported by the Federal Elections Commission (FEC). Second, we disaggregate fundraising into two separate categories - funds received by individual contributions and funds received from political action committee (PAC) contributions. ${ }^{7}$ Similar to our indicator for total fundraising, the individual and PAC measures are relative in that we subtract Republican Party candidate fundraising from Democratic Party candidate fundraising in order to construct the measures (in $\$ 100,000 \mathrm{~s}$ ). All dollar values are standardized in 2014 dollars. Consistent with previous research, we exclude special elections and races in which one candidate is uncontested (Stewart 1989; Abramowitz 1988), as well as races where Google search volume was insufficient to register a score for both candidates. This left 177 individual Senate races between 2004 and 2014.

\footnotetext{
${ }^{5}$ The algorithm that Google uses to estimate search volume is sensitive to sample size. If there are a lot of searches to sample from, Google estimates weekly search traffic over a given timeframe. However, if there is not enough search volume to generate precise estimates, Google estimates monthly rather than weekly search volumes. When collecting the data for this project, Google estimated weekly volumes for most of the races. In those races, attention scores were calculated by summing up the relative search volume for each candidate between the first week in January through the first week of November in each election year and then dividing by the number of weeks in that timeframe. In the few cases where monthly estimates were necessary, attention scores were calculated by averaging across January through November.

${ }^{6}$ We also ran the models using the Democratic candidate's share (as a percentage) or the public attention. The results did not change.

${ }^{7}$ Data for the individual and PAC measures come from www.fec.gov and www.opensecrets.org.
} 


\section{Control Variables}

We include a battery of control variables in order to help replicate prior research on Senate campaign fundraising. Partisanship is measured as the percentage of the two-party vote that the Democratic Party presidential candidate received in each state in the two most recent elections (Bond et al. 1997). Following Jacobson (1992), candidate experience is measured by way of a simple dichotomous indicator, where candidates were coded as 1 if they held any public office prior to the election and 0 if they did not. ${ }^{8}$ To code for open seat races, all races with an incumbent are coded 0 and races without an incumbent candidate as 1 . State income was measured by way of Census Bureau estimates of median state income (using 2-year-average medians). As a proxy for electoral competitiveness, we utilize Westlye's $(1991 ; 1983)$ ex ante measure of campaign intensity. To control for the number of potential donors in each race, we include the natural log of the voting-eligible population in each state (VEP). ${ }^{9}$ To control for media attention, calculate the relative share of newspaper mentions for each candidate between January 1 of the election year and Election Day, via LexisNexis. ${ }^{10}$ Because various scandals may impact fundraising margin, we include a dichotomous measure of scandal, where one equals the presence of a scandal. ${ }^{11}$ Lastly, to control for the noise and idiosyncrasies associated with each election year, we include dummy variables to mark 2004, 2006, 2008, 2010, and 2012, leaving 2014 as the referent category.

\section{Methods and Findings}

In order to explore the relationship between relative public attention and relative fundraising in Senate races, we proceed in two phases. In the first phase, we estimate three OLS models, each of which is summarized in Table 1 (below). The first model regresses relative fundraising on the aforementioned control variables and serves as a baseline to which we compare models two and three. The second model adds our measure of relative attention to the baseline model. The third model interacts public attention with the open seat dichotomous variable in order to test the conditional hypotheses that the impact public attention on fundraising is magnified open seat races. In the second phase, we look at the way in which these models change when fundraising is broken down by source - individual contributions and PAC contributions. Accordingly, we regress relative individual and then relative PAC contributions on the abovementioned set of variables. Table 2 summarizes the results of our phase two analysis. Each OLS model is estimated utilizing robust standard errors if the Breusch-Pagan test for heteroskedasticity is statistically significant. Note that these models do not provide a causal estimate of the impact of public attention on fundraising. Rather, they indicate the presence or

\footnotetext{
${ }^{8}$ The data on challenger experience come from CNN candidate bios.

${ }^{9}$ The VEP data come from Michael McDonald's United States Elections Project: http://elections.gmu.edu/.

${ }^{10}$ Our search criteria included the candidate names plus the word "Senate". To calculate the relative margin, we subtracted the Republican candidate's percentage of newspaper mentions from the Democratic candidate's percentage. Media attention is significantly correlated with public attention $(r=0.77)$, but not so highly as to suggest multicollinearity. Variance inflation factors (VIFs) of the models confirm a lack of multicollinearity.

11 Our scandal measure replicates the LexisNexis-based coding scheme used by Swearingen and Jatkowski (2011).
} 
absence of a relationship between the two variables, when controlling for a number of potentially confounding variables. It is possible (and indeed likely) that the relationship between attention and fundraising is reciprocal--in some cases attention drives fundraising (as we ague above), and in other cases fundraising may generate attention. ${ }^{12}$

12 Understanding the potential endogenous relationship between fundraising and public attention, we looked for a statistically relevant instrumental variable, including the number and percentage of Internet users in each state. Ultimately, we were unable to find an instrument that was "truly" random and either preceded or co-occurred with public attention (see Morgan and Winship 2015). 
Table 1: OLS Models of Relative Total Fundraising in Senate Elections

\begin{tabular}{|c|c|c|c|}
\hline & Base Model & Attention Model & Open Seat Model \\
\hline \multicolumn{4}{|l|}{ Candidate Factors } \\
\hline \multirow[t]{2}{*}{ Democrat Incumbent } & $73.77 * * *$ & $74.29 * * *$ & $90.28 * * *$ \\
\hline & (21.34) & (21.74) & $(23.37)$ \\
\hline \multirow[t]{2}{*}{ Democrat Experience } & $-36.79 *$ & $-36.69 *$ & $-40.11^{*}$ \\
\hline & $(15.18)$ & $(15.40)$ & $(15.77)$ \\
\hline \multirow[t]{2}{*}{ Republican Experience } & 40.13 & 40.05 & 40.77 \\
\hline & $(21.30)$ & $(21.47)$ & $(21.35)$ \\
\hline \multirow[t]{2}{*}{ Democrat Scandal } & -36.55 & -36.26 & -35.06 \\
\hline & $(73.31)$ & $(74.38)$ & $(73.55)$ \\
\hline \multirow[t]{2}{*}{ Republican Scandal } & $68.95^{*}$ & $68.91 *$ & $71.94^{*}$ \\
\hline & $(31.70)$ & $(31.83)$ & (77.44) \\
\hline \multicolumn{4}{|l|}{ Statewide Factors } \\
\hline \multirow[t]{2}{*}{ VEP (natural log) } & 9.79 & 9.69 & 7.87 \\
\hline & $(5.20)$ & $(5.24)$ & $(5.10)$ \\
\hline \multirow[t]{2}{*}{ State Income $(\$ 1,000 \mathrm{~s})$} & -0.47 & -0.48 & -0.47 \\
\hline & $(0.81)$ & $(0.82)$ & $(0.80)$ \\
\hline \multirow[t]{2}{*}{ Democratic Partisanship } & $1.42 *$ & $1.44^{*}$ & $1.48^{*}$ \\
\hline & $(0.68)$ & $(0.69)$ & $(0.70)$ \\
\hline \multicolumn{4}{|l|}{ Campaign Factors } \\
\hline \multirow[t]{2}{*}{ Electoral Competitiveness } & $-29.82 *$ & $-29.81 *$ & $-32.60 *$ \\
\hline & $(12.75)$ & $(12.77)$ & $(12.76)$ \\
\hline \multirow[t]{2}{*}{ Open Seat } & 19.10 & 19.32 & $31.82 *$ \\
\hline & $(14.64)$ & $(14.92)$ & $(16.08)$ \\
\hline \multirow[t]{2}{*}{ Media Attention } & $0.56^{* *}$ & $0.57 * *$ & $0.48^{*}$ \\
\hline & $(0.18)$ & $(0.19)$ & $(0.19)$ \\
\hline \multirow[t]{2}{*}{ Public Attention } & -- & -0.04 & -0.16 \\
\hline & & $(0.31)$ & $(0.30)$ \\
\hline Public Attention x Open Seat & -- & -- & $\begin{array}{c}1.69 * * \\
(0.91)\end{array}$ \\
\hline
\end{tabular}




\begin{tabular}{|c|c|c|c|}
\hline & Base Model & Attention Model & Open Seat Model \\
\hline \multicolumn{4}{|l|}{ Other } \\
\hline \multirow[t]{2}{*}{2004} & 9.48 & 9.72 & 6.63 \\
\hline & (19.35) & (19.61) & (19.85) \\
\hline \multirow[t]{2}{*}{2006} & -7.09 & -6.81 & -10.61 \\
\hline & (13.33) & (13.26) & (13.65) \\
\hline \multirow[t]{2}{*}{2008} & 4.01 & 4.40 & 1.20 \\
\hline & (12.78) & (12.96) & (12.79) \\
\hline 2010 & $\begin{array}{c}-31.80^{*} \\
(15.27)\end{array}$ & $\begin{array}{l}-31.76^{*} \\
(15.40)\end{array}$ & $\begin{array}{c}-35.40^{*} \\
(16.14)\end{array}$ \\
\hline \multirow[t]{2}{*}{2012} & -18.02 & -18.15 & -22.00 \\
\hline & (18.88) & (19.18) & (19.33) \\
\hline \multirow[t]{2}{*}{ Intercept } & $-201.91^{*}$ & $-201.30^{*}$ & $-177.72 *$ \\
\hline & (79.66) & $(79.90)$ & (77.44) \\
\hline F-statistic & $10.39 * * *$ & $9.97 * * *$ & $9.43 * * *$ \\
\hline Adj. $R^{2}$ & 0.41 & 0.41 & 0.42 \\
\hline Breusch-Pagan & $4.10^{*}$ & $4.19^{*}$ & $5.92 *$ \\
\hline $\mathrm{N}$ & 178 & 178 & 178 \\
\hline
\end{tabular}

Although we are primarily interested in the relationship between public attention and relative fundraising, it is useful to briefly comment on the base model (Table 1), which validates our data by corroborating previous research. Beginning with candidate-specific attributes, we find that Republican Party candidate experience is positively associated with the Democratic Party candidate's relative fundraising margin. In the context of Stewart's (1989) findings, that one candidate raises more money as his/her opponent also does so is not surprising. We also find that the presence of a Democrat incumbent increases the Party's fundraising margin by nearly $\$ 7.3$ million. Again, given the built-in fundraising base among incumbents, this is not surprising. A second significant candidate-based variable is the presence of scandal for the GOP candidate. Among the statewide factors, partisanship is the only significant predictor of relative fundraising; the Democratic the state, the larger the fundraising advantage for the Democratic candidate. Finally, among the campaign factors, the base model indicates that Democrats are expected to outraise Republicans in less intense races and when they receive a larger share of the media attention. Overall, this model is statistically significant (F-statistic $=10.39, p<0.001)$ and explains 41 percent of the variation in fundraising margin. 
Though the base model offers important findings that validate the data, the more interesting findings are presented in the public attention and open seat models, which simply add the indicator of relative public attention and then an open seat interaction to the baseline model. In the public attention model the same candidate and statewide factors are statistically significant as in the base model. Relative public attention is not a significant contributor to the incumbent party candidate's fundraising margin.

The significance of relative public attention comes when we interact public attention with open seat elections. Our open seat model, displayed in the third column of Table 1, has the highest adjusted R-Squared (0.42) of the three models. More importantly, the coefficient for the interaction term is both statistically and substantively significant in the expected direction. In open seat elections, a unit increase in relative attention to the Democratic candidate is associated with an expected $\$ 169,000$ increase in relative fundraising margin. Since Democrats in open seats do not enjoy nearly the same level of relative public attention advantage as actual incumbents (mean advantage of -0.74 for the former compared to 1.66 for the latter), those who can maintain a year-long advantage in public attention can bolster their relative fundraising advantage. Based on this finding, candidates have a clear incentive to look for ways to spark public attention in their campaign, whether through speeches, television appearances, or other means. Doing so means more money, which allows for an advantage in campaign activities, whether they be get-out-the-vote (GOTV) drives, field workers, or television ads.

Figure 1: Conditional Effects of Public Attention on Relative Total Fundraising (a) Incumbent in Race (b) Open Seat

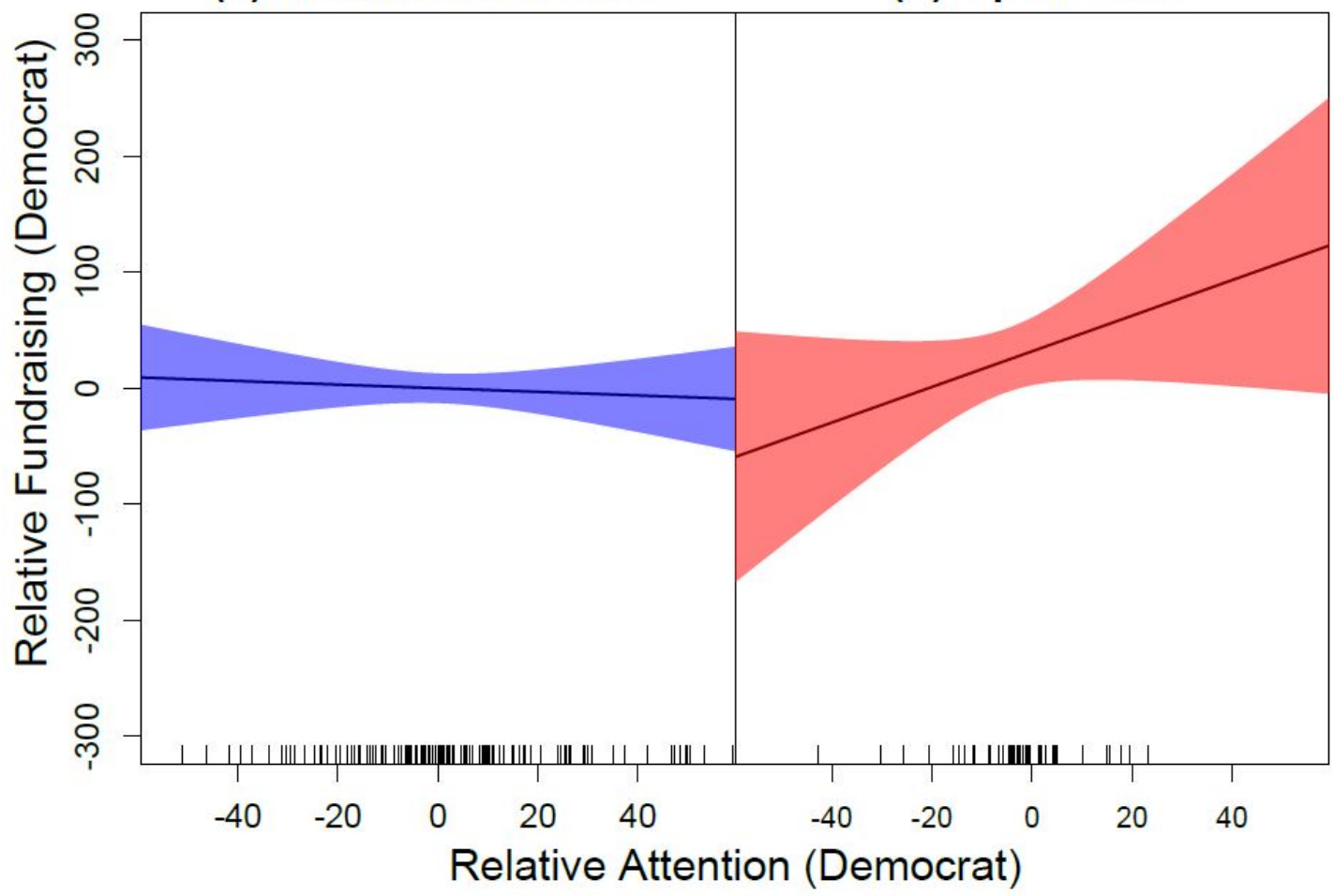

To put this relationship into perspective, Figure 1 plots the conditional effect of relative public attention on relative fundraising in Senate elections. Focusing on the open seat model, we 
see that Democrats who generate the average difference in relative attention are expected to raise approximately $\$ 125,000$ less than their Republican opponents. By comparison, our model predicts that a Democrat who generates significantly more public attention than his or her opponent (by one standard deviation) would raise roughly $\$ 1,000,000$ more than their opponent. Given that the median Democrat faced a very slight fundraising deficit in our timeframe, the extra money would have been useful for additional advertising or GOTV efforts. For instance, in the 2010 New Hampshire open seat race between Paul Hodes (D) and Kelly Ayotte (R), it was Ms. Ayotte who had the relative public attention advantage (6.7 points, about one standard deviation away from the mean). In the end, she outraised Mr. Hodes by nearly $\$ 500,000$ and won the election handily.

Having noted the general relationship between attention and fundraising, it is important to think about the kind of fundraising that are influenced by public attention. Do increased levels of relative attention correlate with campaign contributions by individuals, PACs, or both? To answer this question, phase two of our analysis slightly modifies the open seat model in Table 1 by changing the dependent variable to individual and PAC receipts (standardized at 2014 dollars), but keeping the same battery of independent variables. ${ }^{13}$

\footnotetext{
13 Correlations between net, individual, and PAC receipts range from a low of 0.51 (PAC, Total) to a high of 0.71 (Individual, Total).
} 
Table 2: OLS Models of Relative Individual and PAC Fundraising in Senate Elections

\begin{tabular}{|c|c|c|}
\hline & Individual Receipts & PAC Receipts \\
\hline \multicolumn{3}{|l|}{ Candidate Factors } \\
\hline \multirow[t]{2}{*}{ Democrat Incumbent } & $75.62 * * *$ & $46.90 * * *$ \\
\hline & $(19.10)$ & $(4.10)$ \\
\hline \multirow[t]{2}{*}{ Democrat Experience } & -10.05 & 2.33 \\
\hline & $(10.47)$ & $(2.70)$ \\
\hline \multirow[t]{2}{*}{ Republican Experience } & -11.00 & -0.59 \\
\hline & $(13.30)$ & $(2.37)$ \\
\hline \multirow[t]{2}{*}{ Democrat Scandal } & 40.52 & 1.94 \\
\hline & $(32.95)$ & $(5.08)$ \\
\hline \multirow[t]{2}{*}{ Republican Scandal } & 55.65 & 2.62 \\
\hline & $(41.44)$ & $(3.77)$ \\
\hline \multicolumn{3}{|l|}{ Statewide Factors } \\
\hline \multirow[t]{2}{*}{ VEP (natural log) } & 4.83 & $-1.98 *$ \\
\hline & $(4.96)$ & $(0.99)$ \\
\hline \multirow[t]{2}{*}{ State Income $(\$ 1,000 \mathrm{~s})$} & 0.28 & -0.01 \\
\hline & $(0.53)$ & $(0.13)$ \\
\hline \multirow[t]{2}{*}{ Democratic Partisanship } & $1.56^{*}$ & -0.04 \\
\hline & $(0.65)$ & $(0.13)$ \\
\hline \multicolumn{3}{|l|}{ Campaign Factors } \\
\hline \multirow[t]{2}{*}{ Electoral Competitiveness } & -13.25 & $-3.98 *$ \\
\hline & $(13.15)$ & $(1.96)$ \\
\hline \multirow[t]{2}{*}{ Open Seat } & $41.59 * *$ & $23.84 * * *$ \\
\hline & $(14.33)$ & $(3.05)$ \\
\hline Media Attention & $\begin{array}{c}0.20 \\
(0.12)\end{array}$ & $\begin{array}{l}-0.003 \\
(0.03)\end{array}$ \\
\hline \multirow[t]{2}{*}{ Public Attention } & -0.42 & -0.03 \\
\hline & $(0.22)$ & $(0.06)$ \\
\hline \multirow[t]{2}{*}{ Public Attention x Open Seat } & $1.38 * *$ & $0.52 * * *$ \\
\hline & $(0.50)$ & $(0.16)$ \\
\hline
\end{tabular}




\begin{tabular}{|c|c|c|}
\hline & & \\
\hline & Individual Receipts & PAC Receipts \\
\hline Other & & \\
\hline 2004 & 19.46 & 1.87 \\
\hline & $(16.56)$ & $(3.43)$ \\
\hline 2006 & 9.02 & 1.01 \\
\hline & (14.43) & $(3.11)$ \\
\hline 2008 & -0.28 & 3.15 \\
\hline & (11.66) & $(3.04)$ \\
\hline 2010 & $\begin{array}{c}-18.22 \\
(13.10)\end{array}$ & $\begin{array}{c}3.70 \\
(2.97)\end{array}$ \\
\hline 2012 & -10.61 & 3.83 \\
\hline & $(12.42)$ & $(2.94)$ \\
\hline Intercept & $-167.09^{*}$ & 7.14 \\
\hline & $(79.22)$ & $(15.26)$ \\
\hline F-statistic & $12.81 * * *$ & $35.59 * * *$ \\
\hline Adj. $R^{2}$ & 0.41 & 0.75 \\
\hline Breusch-Pagan & $57.24 * * *$ & 1.09 \\
\hline $\mathrm{N}$ & 177 & 177 \\
\hline
\end{tabular}

$* * * \mathrm{p} \leq .001,{ }^{* *} \mathrm{p} \leq .01, * \mathrm{p} \leq .05 ;$ one-tailed probabilities for hypothesized relationships. Robust standard errors are listed in parentheses. Dependent variable is the Democratic Party candidate's margin $(\$ 100 \mathrm{k})$.

As summarized in Table 2, the more nuanced fundraising models highlight the notion that not all fundraising is the same. For instance, Democratic incumbents tend to receive significantly more individual donations (\$7.6 million) than non-incumbents, although their margin of PAC receipts is smaller ( $\$ 4.7$ million). By comparison, Democrats raise more money from individuals in pro-Democratic states, but state partisanship has no impact on PAC receipts. While electoral competitiveness does not influence individual receipts, Democrats raise more PAC money in less competitive races. Finally, from 2004 to 2014, Democrats did exceptionally well in open seat elections, outraising their Republican counterparts on average by almost $\$ 4.2$ million in individual receipts and \$2.4 million in PAC donations, controlling for other factors. 
Figure 2: Conditional Effects of Public Attention on Relative Individual Receipts (a) Incumbent in Race (b) Open Seat

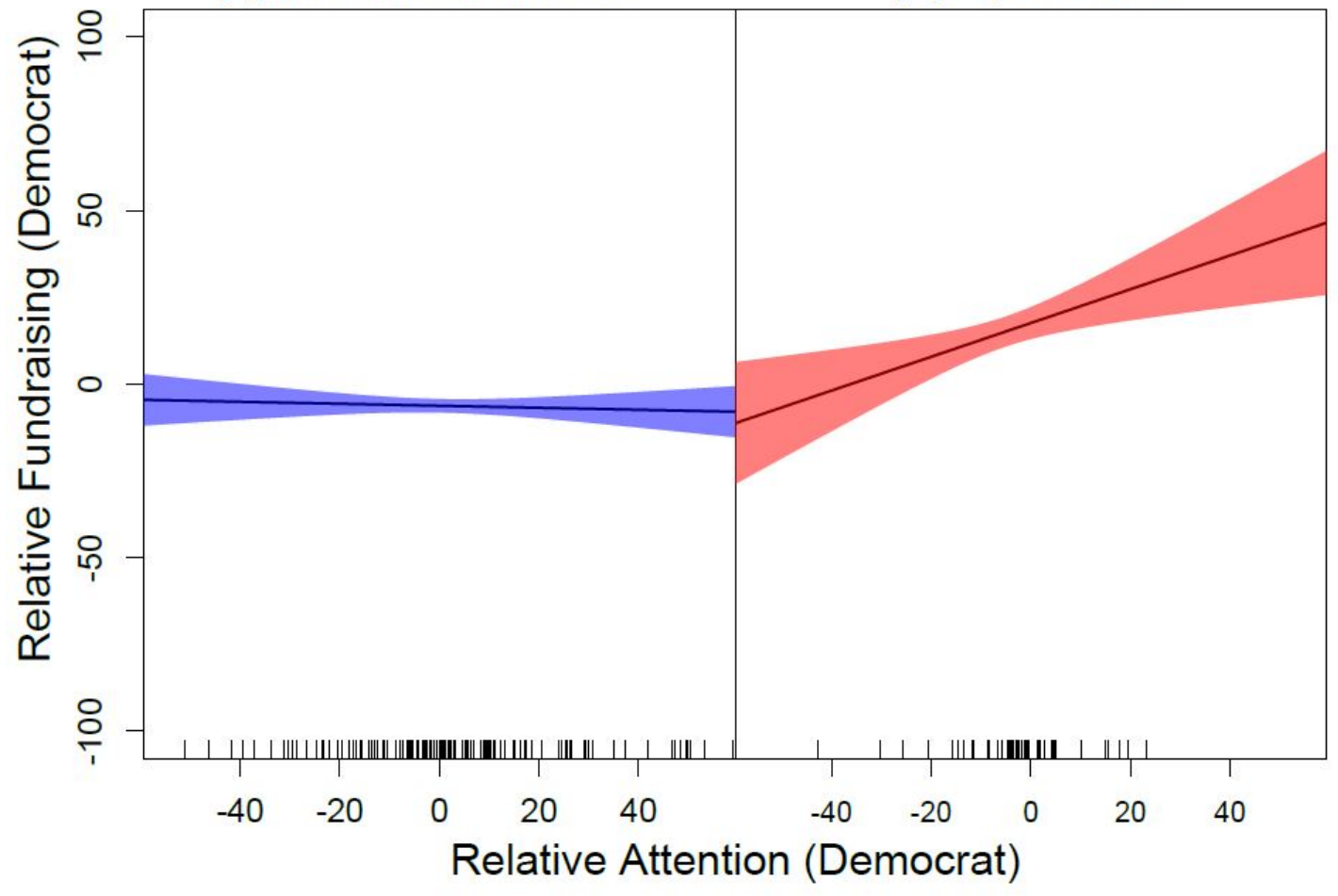

The important similarity between the two models, though, is that the relationship between public attention and fundraising is similar to the first phase of our analysis. Relative attention is not related to individual or PAC contributions in campaigns where an incumbent is running, but it related to both types of fundraising in open seat elections. Figure 2 shows that Democratic Party candidate that generates only the average amount of attention $(-0.74)$ is predicted to generate $\$ 138,000$ less than their challenger in individual contributions. An otherwise comparable Democrat who generates more attention than their challenger (by one standard deviation) is expected to raise an expected $\$ 900,000$ more in individual receipts, which equates to a difference of almost $\$ 800,000$. By comparison Democrat who generates an average amount of attention is predicted to raise \$52,000 less in PAC contributions than their opponent. A similar Democrat who creates a larger attention gap (by one standard deviation) is expected to raise $\$ 335,000$ more in PAC donations (Figure 3). In other words, increased levels of public attention are associated with increases in both types of fundraising.

Whether examining total fundraising margin, individual receipts, or PAC donations, these findings highlight the relevance of public attention in open seat elections. This analysis reflects the words of Krasno, Green, and Cowden (1994, 459), that candidates "generally have to spend money to win elections". In order to spend resources on campaign activities, candidates have to find ways to raise money. While this may mean hiring additional fundraising consultants or holding more large-donor events, it also includes increasing their share of public attention. 
Figure 3: Conditional Effects of Public Attention on Relative PAC Receipts

(a) Incumbent in Race

(b) Open Seat

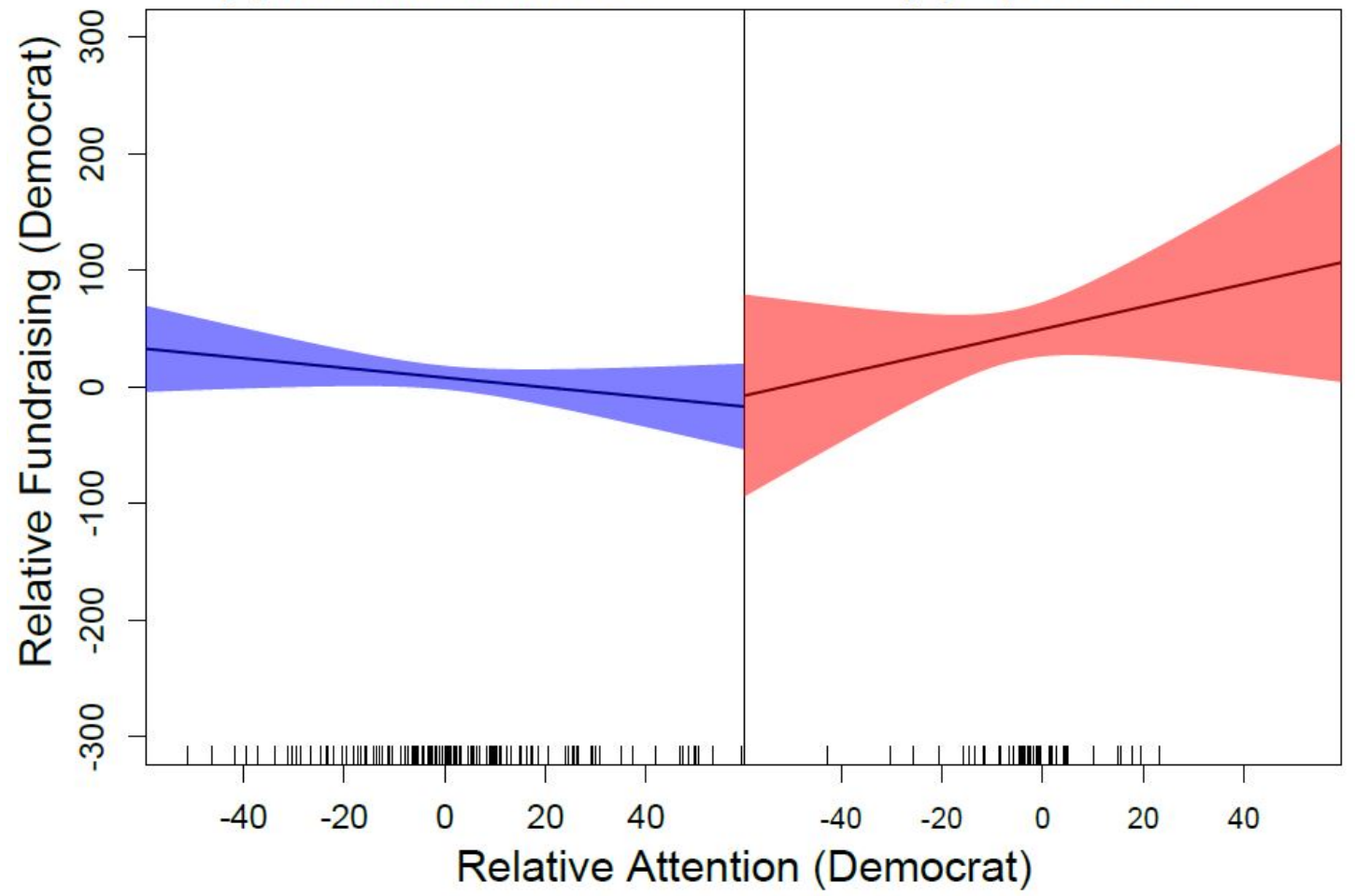

\section{Discussion and Conclusion}

Our findings suggest that public attention deserves greater consideration in the explanation of political phenomena, especially campaign and election outcomes. Through the analysis of all Senate general election campaigns from 2004 to through 2014, we find that there is a strong positive relationship between public attention and relative fundraising. This finding is consistent with the sequential view of campaign processes (e.g., Stewart, 1989): candidates and campaigns that are able to stimulate a competitive advantage in public attention may in turn reap the benefits through an increasing advantage in relative fundraising - including individual and PAC contributions. If people are paying attention to you more than they are to your opponent, you are likely to experience a fundraising advantage. Given the influence of fundraising on election outcomes, this finding makes a substantial contribution to the knowledge of political campaigns. In congressional races, candidates and campaigns should strategically act to draw the public's eye.

Finding that public attention relates to fundraising in congressional elections provides the opportunity to build more dynamic models fundraising success. We suggest that future scholarship leverage this dynamic to address outstanding questions about causality and the candidate-campaign activities that produces "good" vs. "bad" attention. Does public attention generate fundraising, or does fundraising lead to attention? Is all attention "good" attention, or do some types of attention (i.e., attention prompted by a gaffe) hurt fundraising efforts? In-depth investigation of individual races over time with help to answer these questions. To illustrate this point, we briefly examined the 2012 open seat Senate race in Nevada between Shelley Berkley 
(D) and Dean Heller (R) and the 2006 Senate race in Virginia between then-Senator George Allen (R-incumbent) and Jim Webb (D).

Beginning with causality, we used the temporal dynamics in the Berkley-Heller race to investigate the "order" of the relationship between attention and fundraising. We selected the Berkley-Heller race because relative attention and fundraising varied rather substantially throughout the course of the race. This variance is shown in Figure 4, which plots relative attention and fundraising (individual contributions) by week from January of 2012 through the beginning of November of 2012. On average, Heller (the eventual winner) received more attention and raised more money than Berkley, but Berkley had several positive weeks, both in terms of attention and fundraising. Though each change in attention/fundraising is interesting, the general trend in Figure 4 suggests that notable changes in attention generally lead changes in fundraising. This is true of increases in attention, which correspond with increases in fundraising in the week that follows, and decreases in attention that are followed by decreases in fundraising. 
Figure 4: Relative Individual Receipts vs. Relative Attention in the 2012 Berkley-Heller Senate Race

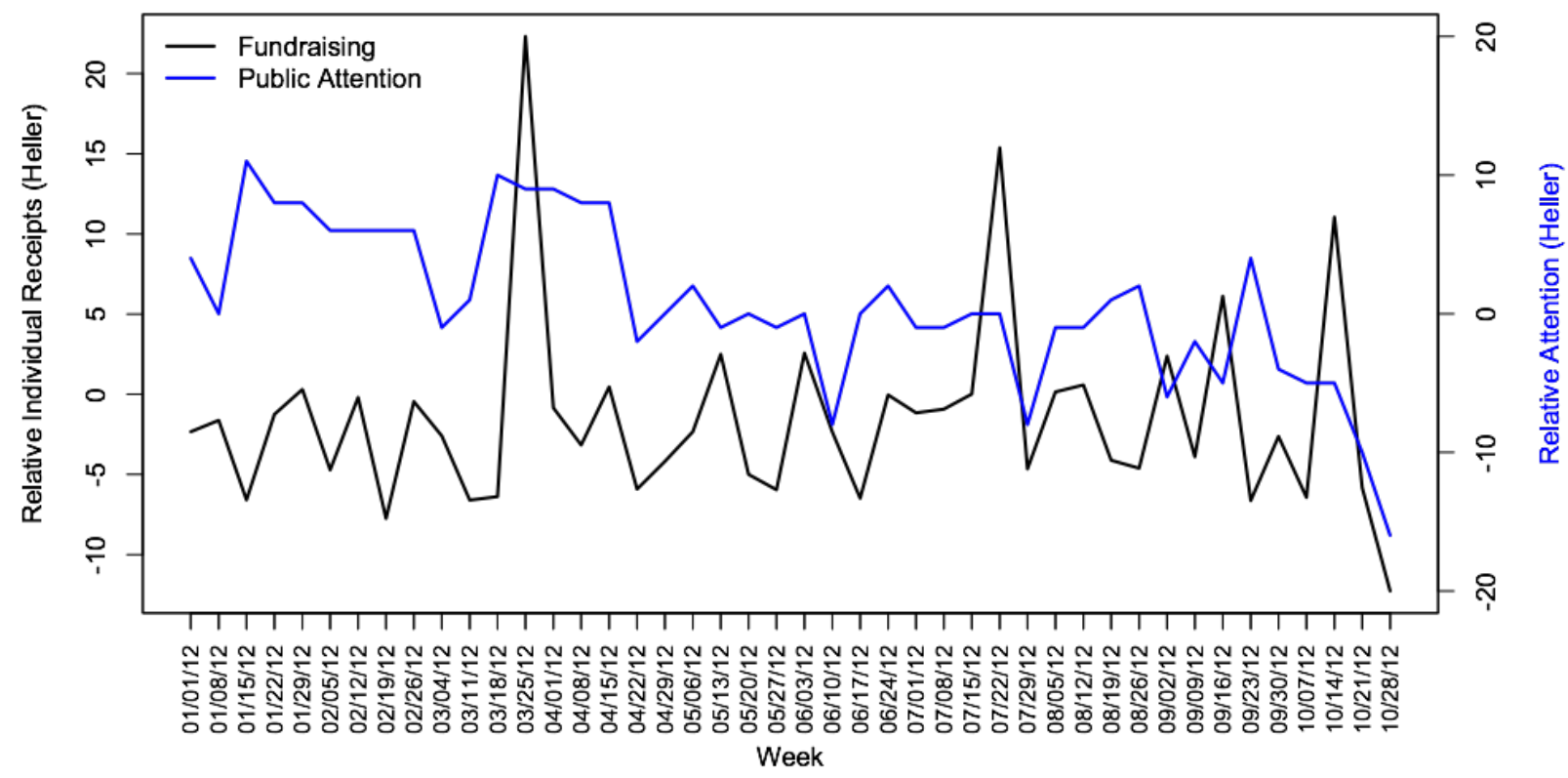

To corroborate this general trend, we used Granger causality tests to identify the temporal association between the two variables. ${ }^{14}$ The tests indicated that relative attention "Grangercaused" relative fundraising $(\mathrm{F}$-statistic $=8.348$; $\mathrm{p}$-value $=0.006)$, whereas relative fundraising did not "Granger-cause" relative attention $(\mathrm{F}$-statistic $=0.753$; $\mathrm{p}$-value $=0.391)$. These results are consistent with the causal theory outlined in this study, that attention leads to fundraising. However, it is possible (and indeed likely) that fundraising, and the activities that correspond with fundraising, generate public attention in some races. We expect that the measure and theory we have outlined in this study will encourage future investigation into when and how this might happen.

Moving now to the idea of "bad" attention, the Allen-Web race provides an important cautionary tale for Senate candidates that would do anything to grab attention. To investigate this case, we collected weekly relative public attention and relative fundraising data for both candidates from January of 2006 through September of 2006. During this time period, there is a significant and negative correlation between relative public attention advantages for Allen and relative fundraising outcomes. Figure 4 provides a visual demonstration of the relationship. While there is clearly a sharp divergence in George Allen's public attention advantage and an exploding relative fundraising disadvantage after the notorious "macaca incident," the Allen campaign was consistently unable to turn a maintained public attention advantage into relative fundraising success. Given the importance of fundraising on campaign success, after looking at Figure 4 one would not be surprised that Jim Webb ultimately won this race, upsetting the incumbent Senator. Certainly the 2006 elections were influenced by other factors as well, the

\footnotetext{
14 The variables were non-stationary, so the Granger causality tests were done using first differences. Fit statistics indicated that one week was the appropriate lag time for both tests.
} 
anti-Republican mood for example, yet it appears that all attention is not necessarily "good attention." "Bad attention" is possible.

Figure 5: Relative Individual Receipts vs. Relative Attention in the 2006 Allen-Webb Senate

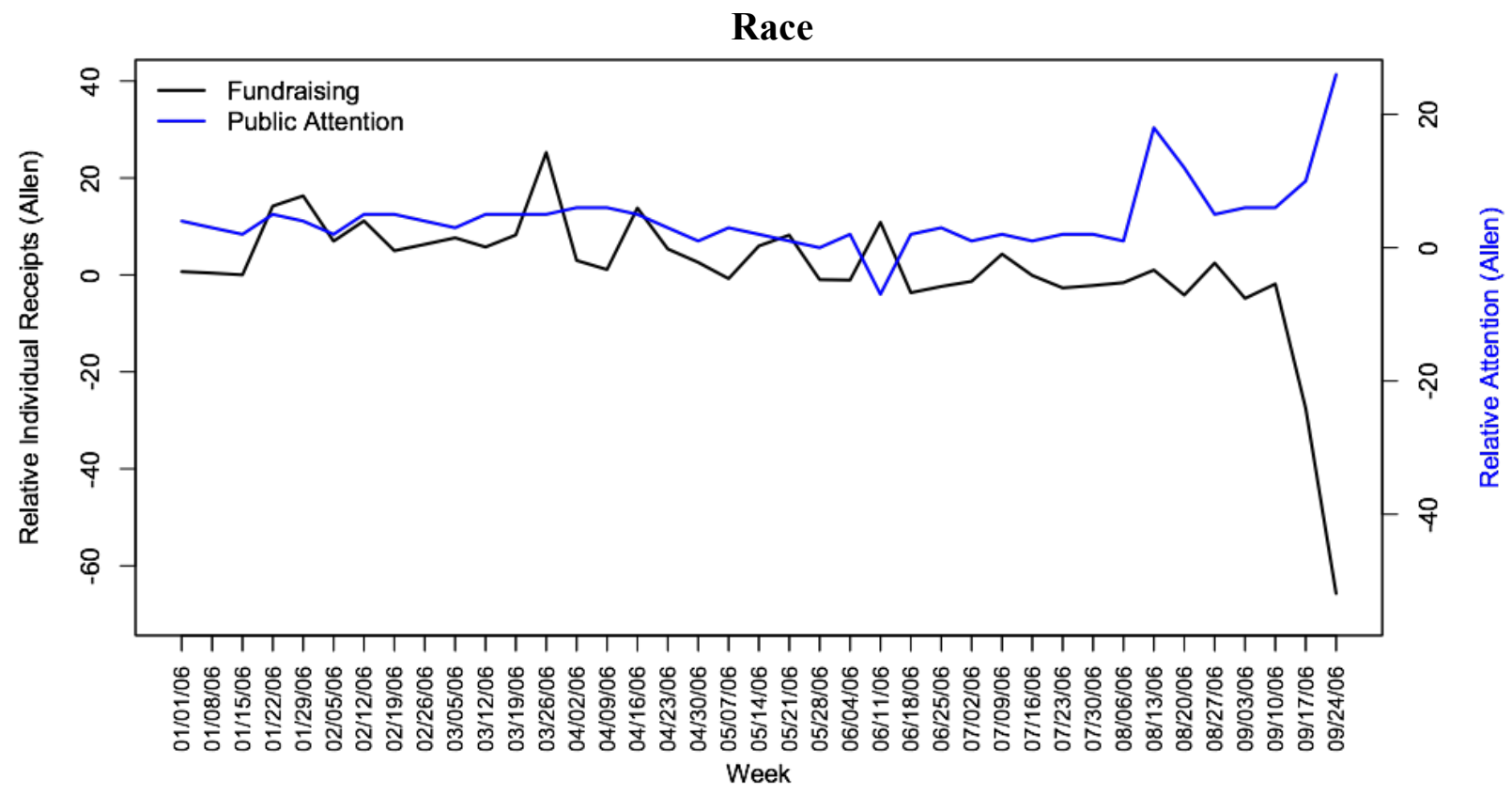

A look at the Allen/Webb case suggests that actions and events by candidates and campaigns influence public behavior toward campaigns. It appears the Allen campaign was ineffective at building on existing attention and fundraising advantages throughout the election year. The inability to transform the attention advantage into a substantive fundraising advantage left the challenger, Webb, with an opening to win the race. In our statistical analysis of this case, that we unable to find a significant time-based relationship between the "macaca incident" and the impact of Allen's attention advantage suggests that Allen and his campaign simply failed to provide the type of events or actions to galvanize its consistent public attention advantage. Possibly, because the campaign was unable to turn the public attention advantage into fundraising gains, the presumably negative public attention following the August incident only served to exacerbate the already negative fundraising impact of an ineffective and ineffectual campaign.

This brief examination of a single case suggests that public attention advantages play a significant role in campaign outcomes and deserve further investigation from political scientists. Certainly, understanding the importance of public attention in open seat races is critical given that open seats are the primary source of membership change in Congress, however the impact of public attention on incumbent races must be explored further. Do incumbents have a natural advantage in relative attention and fundraising that must be capitalized on to impact campaign outcomes? When could public attention be a "bad" thing for incumbent candidates? How and under what circumstances do candidate and campaign actions and events capture the curiosity of the public? Answering these questions will not only build on the scholarly understanding of 
public attention's impact on political phenomena, but also provide practical implications for political campaigns and consultants. Applying the concept of public attention to political phenomena is an agenda worthy of further examination. 


\section{Appendices}

Appendix A: Descriptive Statistics for Interval-Level Variables

\begin{tabular}{|c|c|c|c|c|c|}
\hline Variable & Mean & Median & Minimum & Maximum & Std. Deviation \\
\hline \multicolumn{6}{|l|}{ Dependent Variables $^{a}$} \\
\hline Total Fundraising (\$100k) & 4.83 & -1.36 & -452.90 & 397.61 & 87.16 \\
\hline Individual Receipts (\$100k) & 14.19 & 11.03 & -144.36 & 492.01 & 69.36 \\
\hline PAC Receipts (\$100k) & -0.87 & -1.38 & -51.34 & 55.69 & 22.85 \\
\hline \multicolumn{6}{|l|}{ Explanatory Variables } \\
\hline Relative Public Attention & 1.66 & -0.19 & -73.10 & 63.64 & 23.53 \\
\hline $\begin{array}{l}\text { Relative Public Attention } \\
\text { (open seat) }\end{array}$ & -0.74 & 0.00 & -42.82 & 23.1 & 6.42 \\
\hline Media Attention & 2.76 & -2.28 & -100 & 100 & 60.48 \\
\hline Partisanship & 48.92 & 48.80 & 27.50 & 72.40 & 9.32 \\
\hline State Median Income & 50,128 & 49,158 & 34,733 & 73,397 & 8,289 \\
\hline
\end{tabular}

${ }^{a}$ Measured as the incumbent party candidate margin. 


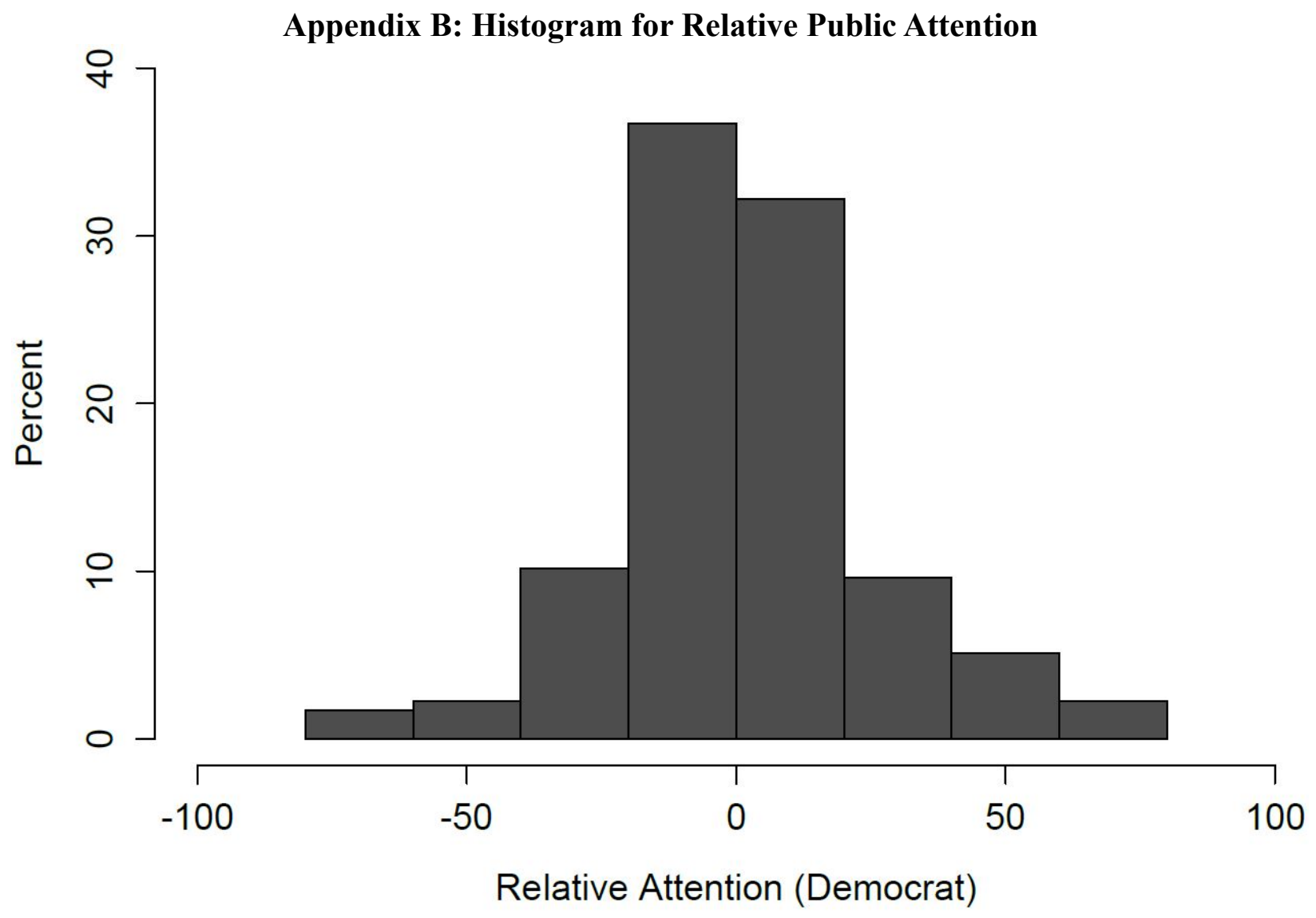




\section{Works Cited}

Abramowitz, Alan I. 1988. "Explaining Senate Election Outcomes." The American Political Science Review 82 (2): 385-403. doi:10.2307/1957392.

Adams, Greg D., and Peverill Squire. 1997. "Incumbent Vulnerability and Challenger Emergence in Senate Elections.” Political Behavior 19 (2): 97-111. doi:10.2307/586474.

Askitas, Nikos, and Klaus Zimmermann. 2009. "Google Econometrics and Unemployment Forecasting.” http://papers.ssrn.com/sol3/papers.cfm?abstract_id=1465341.

Ayers, John W., Kurt Rubisl, and John S. Brownstein. 2011. "Using Search Query Surveillance to Monitor Tax Avoidance and Smoking Cessation Following the United States' 2009 'SCHIP' Cigarette Tax Increase.” PLoS ONE 6 (e16777).

Behr, Roy L., and Shanto Iyengar. 1985. "Television News, Real-World Cues, and Changes in the Public Agenda.” Public Opinion Quarterly 49 (1): 38. doi:10.1086/268900.

Bond, Jon R., Richard Fleisher, and Jeffery C. Talbert. 1997. "Partisan Differences in Candidate Quality in Open Seat House Races, 1976-1994." Political Research Quarterly 50 (2): 281-99. doi:10.2307/448958.

Epstein, David, and Peter Zemsky. 1995. "Money Talks: Deterring Quality Challengers in Congressional Elections." The American Political Science Review 89 (2): 295-308. doi: $10.2307 / 2082426$.

Eshbaugh-Soha, Matthew. 2006. "The Conditioning Effects of Policy Salience and Complexity on American Political Institutions.” Policy Studies Journal 34 (2): 223-43. doi:10.1111/j. 1541-0072.2006.00167.x.

Falkinger, Josef. 2008. "Limited Attention as a Scarce Resource in Information-Rich Economies." The Economic Journal 118 (532): 1596-1620. doi:10.2307/20108876.

Flemming, Roy B., B. Dan Wood, and John Bohte. 1999. "Attention to Issues in a System of Separated Powers: The Macrodynamics of American Policy Agendas.” The Journal of Politics 61 (1): 76-108. doi:10.2307/2647776.

Gaddie, Ronald Keith, and Charles S. Bullock. 2000. Elections to Open Seats in the US House: Where the Action Is. Rowman \& Littlefield.

Gerber, Alan. 1998. "Estimating the Effect of Campaign Spending on Senate Election Outcomes Using Instrumental Variables." The American Political Science Review 92 (2): 401-11. doi: $10.2307 / 2585672$.

Gimpel, James G., Karen M. Kaufmann, and Shanna Pearson-Merkowitz. 2007. "Battleground States versus Blackout States: The Behavioral Implications of Modern Presidential Campaigns." The Journal of Politics 69 (3): 786-97.

Goldenberg, Edie N., and Michael W. Traugott. 1980. "Congressional Campaign Effects on Candidate Recognition and Evaluation." Political Behavior 2 (1): 61-90. doi: $10.2307 / 586427$.

Gormley, William T. 1986. "Regulatory Issue Networks in a Federal System.” Polity 18 (4): 595. doi:10.2307/3234884.

Granka, Laura. 2013. "Using Online Search Traffic to Predict US Presidential Elections.” PS: Political Science \& Politics 46 (2): 271-79. doi:10.1017/S1049096513000292.

Grier, Kevin B. 1989. “Campaign Spending and Senate Elections, 1978-84.” Public Choice 63 (3): 201-19. doi:10.2307/30025191. 
Gruszczynski, Michael W., and Michael W. Wagner. 2010. "Google It: A New Way to Measure the Agenda-Setting Effect.” In . Vol. 26.

Henry, Gary T., and Craig S. Gordon. 2001. "Tracking Issue Attention: Specifying the Dynamics of the Public Agenda." The Public Opinion Quarterly 65 (2): 157-77. doi: $10.2307 / 3078800$.

Jacobson, Gary C. 1992. The Politics of Congressional Elections. 3rd ed. New York: HarperCollins. http://www.citeulike.org/group/582/article/369482.

Jennings, Will, and Peter John. 2009. "The Dynamics of Political Attention: Public Opinion and the Queen's Speech in the United Kingdom." American Journal of Political Science 53 (4): 838-54. doi:10.2307/20647954.

Jones, Bryan D., and Frank R. Baumgartner. 2005. The Politics of Attention: How Government Prioritizes Problems. Chicago: University of Chicago Press.

Koehler-Derrick, Gabriel. 2013. "Quantifying Anecdotes: Google Search Data and Political Developments in Egypt." PS: Political Science \& Politics 46 (2): 291-98. doi:10.1017/ S1049096513000267.

Krasno, Jonathan S., Donald Philip Green, and Jonathan A. Cowden. 1994. "The Dynamics of Campaign Fundraising in House Elections." The Journal of Politics 56 (2): 459-74. doi: $10.2307 / 2132148$.

Lazarus, Jeffrey. 2008. "Why Do Experienced Challengers Do Better than Amateurs?" Political Behavior 30 (2): 185-98. doi:10.1007/s11109-007-9046-5.

Mayhew, David R. 1974. "Congressional Elections: The Case of the Vanishing Marginals." Polity 6 (3): 295. doi:10.2307/3233931.

Mccallum, Malcolm L., and Gwendolyn W. Bury. 2013. "Google Search Patterns Suggest Declining Interest in the Environment." Biodiversity and Conservation 22 (6-7): 135567. doi:10.1007/s10531-013-0476-6.

Mellon, Jonathan. 2013. "Where and When Can We Use Google Trends to Measure Issue Salience?" PS: Political Science \& Politics 46 (2): 280-90. doi:10.1017/ S1049096513000279.

Mixon, Jr., Franklin G., Chena C. Crocker, and H. Tyrone Black. 2005. "Pivotal Power Brokers: Theory and Evidence on Political Fundraising." Public Choice 123 (3/4): 477-93. doi: $10.2307 / 30026696$.

Mondria, Jordi, Thomas Wu, and Yi Zhang. 2010. "The Determinants of International Investment and Attention Allocation: Using Internet Search Query Data." Journal of International Economics 82 (1): 85-95.

Morgan, Stephen L., and Christopher Winship. 2015. Counterfactuals and Causal Inference: Methods and Principles for Social Research. Second Edition. Analytical Methods for Social Research. New York, NY: Cambridge University Press.

Neuman, W. Russell. 1990. "The Threshold of Public Attention." The Public Opinion Quarterly 54 (2): 159-76. doi:10.2307/2749448.

Newig, Jens. 2004. "Public Attention, Political Action: The Example of Environmental Regulation." Rationality and Society 16 (2): 149-190. 
Pelat, Camille, Clement Turbelin, Avner Bar-Hen, Antoine Flahault, and Alain-Jacques Valleron. 2009. "More Diseases Tracked by Using Google Trends." Emerging Infectious Diseases 15 (8): 1327.

Ragas, M. W., and H. Tran. 2013. "Beyond Cognitions: A Longitudinal Study of Online Search Salience and Media Coverage of the President." Journalism \& Mass Communication Quarterly 90 (3): 478-99. doi:10.1177/1077699013493792.

Reilly, S., S. Richey, and J. B. Taylor. 2012. "Using Google Search Data for State Politics Research: An Empirical Validity Test Using Roll-Off Data." State Politics \& Policy Quarterly 12 (2): 146-59. doi:10.1177/1532440012438889.

Ripberger, Joseph T. 2011. "Capturing Curiosity: Using Internet Search Trends to Measure Public Attentiveness.” Policy Studies Journal 39 (2): 239-259.

Scharkow, Michael, and Jens Vogelgesang. 2011. "Measuring the Public Agenda Using Search Engine Queries." International Journal of Public Opinion Research 23 (1): 104-113.

Scheitle, Christopher P. 2011. "Google's Insights for Search: A Note Evaluating the Use of Search Engine Data in Social Research*." Social Science Quarterly 92 (1): 285-295.

Squire, Peverill, and John R. Wright. 1990. "Fundraising by Nonincumbent Candidates for the U. S. House of Representatives." Legislative Studies Quarterly 15 (1): 89-98. doi: $10.2307 / 440003$.

Stewart, Charles. 1989. "A Sequential Model of U. S. Senate Elections." Legislative Studies Quarterly 14 (4): 567-601. doi:10.2307/439959.

Swearingen, C. Douglas, and Walt Jatkowski. 2011. "Is Timing Everything? Retirement and Seat Maintenance in the US House of Representatives." Legislative Studies Quarterly 36 (2): 309-330.

Swearingen, C. Douglas, and Joseph T. Ripberger. 2014. "Google Insights and U.S. Senate Elections: Does Search Traffic Provide a Valid Measure of Public Attention to Political Candidates?: Google Insights and U.S. Senate Elections." Social Science Quarterly 95 (3): 882-93. doi:10.1111/ssqu.12075.

Westlye, Mark C. 1983. "Competitiveness of Senate Seats and Voting Behavior in Senate Elections." American Journal of Political Science 27 (2): 253. doi:10.2307/2111017. - 1991. Senate Elections and Campaign Intensity. Baltimore: Johns Hopkins University Press.

Wlezien, Christopher. 2005. "On the Salience of Political Issues: The Problem with 'most Important Problem."” Electoral Studies 24 (4): 555-579.

Zheluk, Andrey, Casey Quinn, Daniel Hercz, and James A Gillespie. 2013. "Internet Search Patterns of Human Immunodeficiency Virus and the Digital Divide in the Russian Federation: Infoveillance Study.” Journal of Medical Internet Research 15 (11): e256. doi:10.2196/jmir.2936.

Zhu, Jian-Hua. 1992. "Issue Competition and Attention Distraction: A Zero-Sum Theory of Agenda-Setting." Journalism \& Mass Communication Quarterly 69 (4): 825-836.

Zheluk, A., J. A. Gillespie, and C. Quinn, 2012: Searching for Truth: Internet Search Patterns as a Method of Investigating Online Responses to a Russian Illicit Drug Policy Debate. Journal of Medical Internet Research 14 (6), e165. doi:10.2196/jmir.2270. 